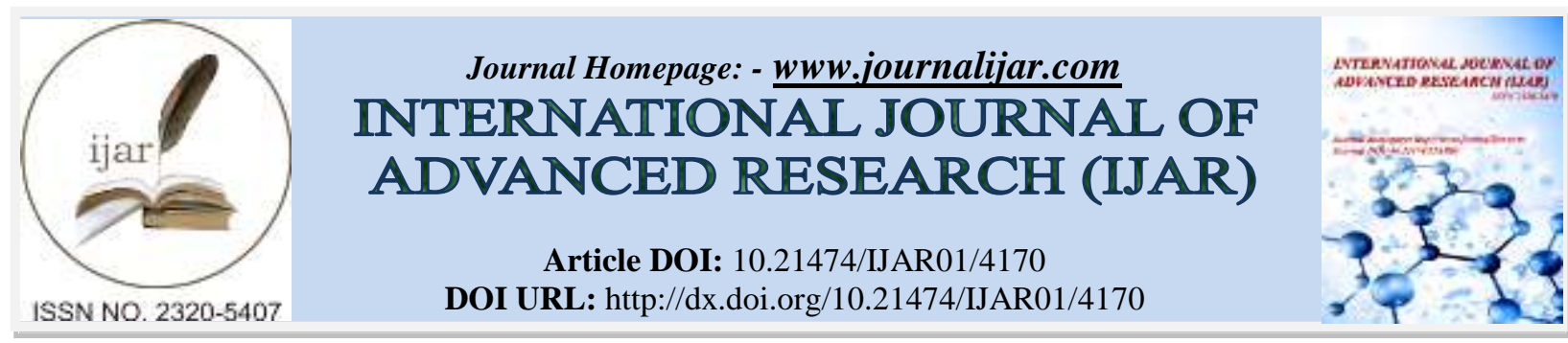

RESEARCH ARTICLE

\title{
INFORMATION AND COMMUNICATION TECHNOLOGIES ACCESSIBILITY ISSUES FACED BY VISUAL IMPAIRED PERSONS.
}

\section{Quratulain Soomro ${ }^{1}$, Sajida Parveen ${ }^{2, *}$ and Nadeem Naeem ${ }^{3}$.}

1. IT Department, Quaid-e-awam university of engineering, science and technology, Nawabshah, Pakistan.

2. Computer systems engineering department, Quaid-e-awam university of engineering, science and technology, Nawabshah, Pakistan.

3. Electronic Engineering department, Quaid-e-awam university of engineering, science and technology, Nawabshah, Pakistan

\section{Manuscript Info}

Manuscript History

Received: 20 March 2017

Final Accepted: 15 April 2017

Published: May 2017

\section{Key words:-}

Information \& communication

Technology, visual Impaired person,

Assistive Technology and computer usage per week

\section{Abstract}

The expeditious growth of Information and Communication Technology (ICT) for a normal person, as a part of global village, explores the world easily, efficiently, and pleasurably but persons with visual impairment face difficulties in accessing these modern communication facilities. The scope of this research was to analyze the accessibility and usability issues faced by disable persons on daily basis. These persons need a specific device or assistive technology that enables them to access computer and get their desired goals accomplished. This research was conducted on the visual impaired persons in Special Education Institute. Questionnaires and interview sessions were carefully designed and conducted to produce significant results and findings towards gaining insight their problems and the possible solutions for the best usage of ICT among the special persons. Usability test was conducted and comparison between two popular screen readers JAWS (Job access with speech) and NVDA (non-visual desktop access) for visual impaired persons is presented for analyzing the better performance.

\section{Introduction:-}

Being a part of this global village, it is a right of every visual impaired person to avail the same facilities as a normal persons are getting, they must have the equal right of accessibility. With growing needs, assistive technology has gained a lot of popularity in order to improve the accessibility of visual impaired people. These tools are called Assistive Technology (AT) tools [1]. There are software designed and currently available in the market to help special persons but still the QUEST continues for better and improved performance. This research paper focuses on screen reader software, which serves as Assistive Technology tools for blind or visual impaired people. These screen reader software play a vital role in ICT accessibility. These screen reader software work best for blind/visual impaired people, which describes that what is being displayed on computer screen. Visual impaired persons can contribute a lot for country's growth and development if they are well aware and equipped with assistive technology tools. The use of assistive technology comprises more than overcome situation hindrances it also attracts and raises a change of symbolic, past and traditional contexts. Assistive technologies are laden with cooperative social literary 
symbols and principles, as well as person approach and meanings assigned to the technology [2,3,4]. Disabled people can adopt assistive technology to pursue to make the different variety of the technology reliable with their favourite own identity. Different research studies showed that when disabled adults seek that analogue assistive technologies, such as examination aid, prostheses and wheelchairs, come to symbolise an identity that marks them as different, they reject the assistive technology [5,6]. While these studies indicated that the use of analogue assistive technologies by adults the research was focused on young people amalgamation of information and communication technologies and ICT assistive technology in order to show which technology transmits the most significant symbols in their daily lives [7,8]. The important objective of the visual assistive technology for computer and other technologies have provided best possible vision improvement or sight exchange device. However, sighted people such important magnifying the screen display in order to facilitate the performance of visual tasks such as reading scripts, choosing menus, replying to system prompts and navigating between different parts of web sites [9]

\section{Information and Communication Technology Accessibility:-}

Accessibility is the quality of being at hand when needed or it is an attribute of being easy to meet or deal with. Accessibility through communication tools means to make any system accessible for a visual impaired person to use the computer applications with the help of assistive technology.

Accessibility helps special people to access modern trends in information communication technology and to eliminate the communication barriers. Accessibility encourages software programmers to design more sophisticated and advanced tools to improve the life of visual impaired people [10]. Fig.1 shows the accessibility model for visual impaired people.

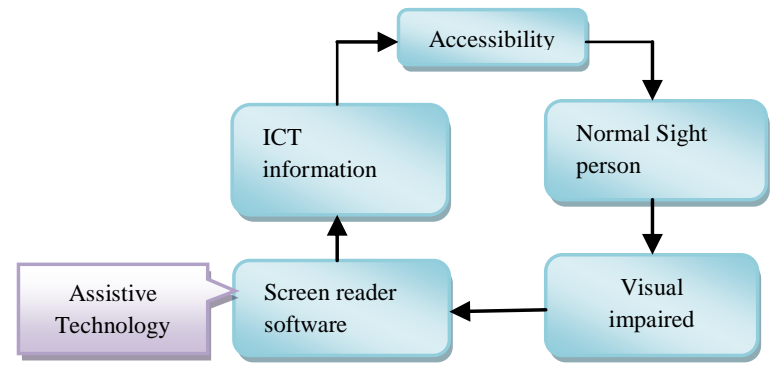

Figure 1:- Accessibility model for visual impaired people.

In general, the term accessibility belongs to the system designed for direct access approach. This is about making systems more approachable to every person whether they have a disability or not. The alternative to this is an indirect access, which provides a kind of support to the use of a person's assistive technology to get access like computer screen reader software.

Technological advancements in information technology made assistive tools more sophisticated. Before that, access to the technology was restricted to those who can afford it, but with growing need it has become more widely used and spread all over in Western countries in recent years. It provides the ability to access information and services by minimizing the barriers of distance and cost as well as the accessibility and usability of the interface for those who use it. Assistive technology gets regularized now in many countries for providing universal access to the internet and telephone systems at bearable cost to citizens [11]. Accessibility is different from usability, the term usability is related to the product such as any device and environment or any service can be used by specific users to get certain tasks effectively with efficiency and contentment in a specified background of use [12,13].

\section{Usability:-}

ISO 9241 [14] defines usability as "The extent to which a product can be used by specified users to achieve specified goals with effectiveness, efficiency, and satisfaction in a specified context of use". Usability can be considered as the ease of use and ability to learn human made product. The product can be any software application or a web access, a book, machine or any system a person interacts with. Usability analysts conduct study on how to make things usable for people. Usability is a major issue in consumer electronics, telecommunications and knowledge transfer items such as any document or online help. Usability is also considered in mechanical objects like door handle. Usability includes the methods of how to measure it, for example analysis of needs [13] and the rules and regulations, which form basis for an object to perceive efficiency. Usability studies the clarity and easiness in the interaction with a computer program or a web site. 


\section{Usability Testing:-}

Usability testing is a method by which users of a product are asked to perform some specific tasks in an effort to measure the product's ease-of-use, task time, and the user's perception of the experience [15]. Usability testing can be done formally or informally. Formal testing can be done in the lab with video camera and informal testing can be done with paper questionnaires, interviews and web browsing. In both methods, usability test participants are encouraged to give their opinion and comments. The usability-testing model is described in fig. 2

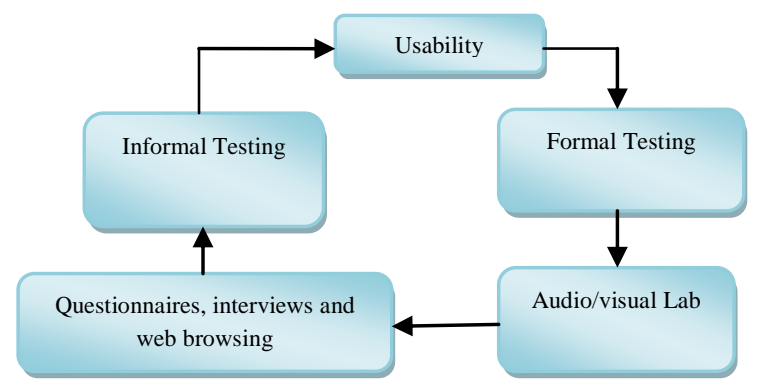

Figure 2:- Usability test model.

Usability testing design must be easy to use, understandable and user friendly. This will make the test quite easy to remember and supportive to the users.

It was proposed that usability testing should be focused on level of users and the tasks given to them, time and error to complete the task [16].

The pre and post-test questionnaires and tasks have been design for the visual impaired persons according to their issues which they have mentioned in their interviews, open discussions and observe in field visit. Three tasks were identified which are performed frequently by the visual users on screen reader software. All three tasks performed by the group of 15 users by using both screen reader software JAWS ${ }^{\circledR}$ and NVDA ${ }^{\circledR}$. These 15 users are studying in different standards and have different age group. Usability test was divided into three tasks:

1. To find any particular website

2. Check emails and

3. Read any news paper

\section{Materials and Methods:-}

The article draws a quantitative interview from 15 students. The sample random were used for data collection from visually impaired young. The 14 male and only one female participated in this study and the education level of the students were six of them were high school matriculation and 4 were middle and 4 were primary school. The participants were selected from the Special Education Institute for visual impaired /blind, deaf and dumb, Government of Sindh, Nawabshah.

\section{Pre-Test Questionaire:-}

Graph 1 is showing 15 users. From which one female and 14 are male students participated in usability test and performs all three tasks which are mentioned above.

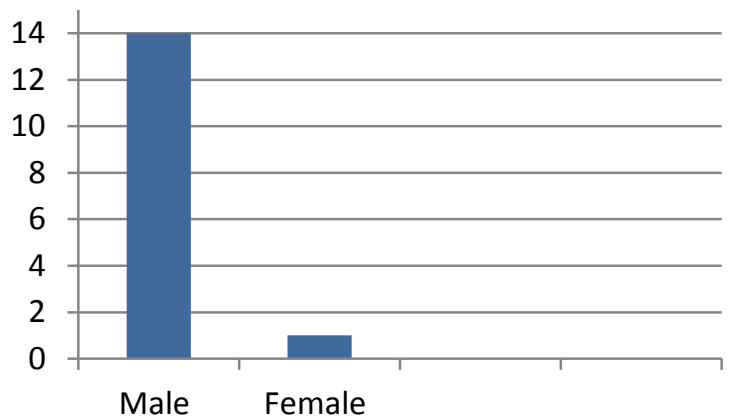

Graph 1:- Pre-test questionnaire. 


\section{Computer Usage Per week:-}

Data from graph 2 showed that user's visual impaired persons (VIP) from different age group who uses the computer technology with respect to their time per week. The study showed that 18 to 16 years old student used 14 hours computer in a week similarly 14 to 12 years old student used 11 hours in a week. However, 10 to 8 years old student used computer 10 hours in a week only 4 hours use computer which age was 8-6 year. It indicated that the student whose age was more than 16 years were more familiar with computer technology and use properly in a week.

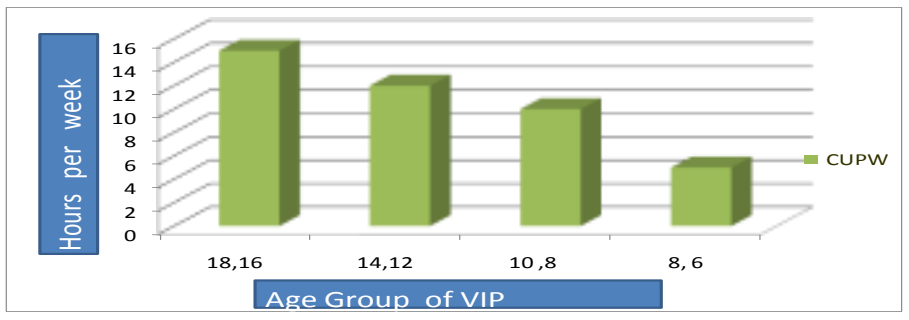

Graph 2:- Computer usage per week.

\section{Educational level of test participants:-}

The educational level of visual impaired participants (students) were summarized in graph 3. In all participants, four students participated from intermediate, five students from high school level and another four middle school students participated in usability testing. This information is summarized in graph 3 as:

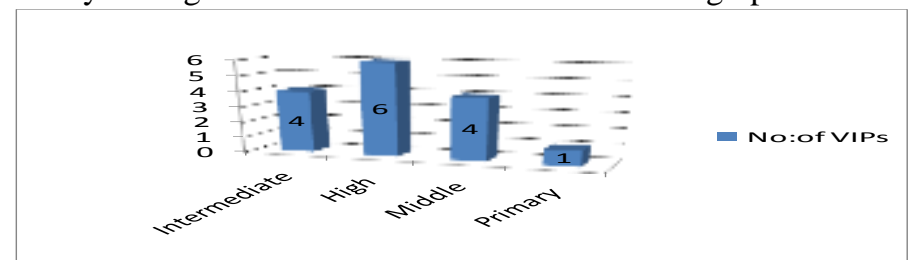

Graph 3:- Educational levels of visual impaired persons.

\section{Usability Testing Results:-}

The usability test was conducted on following parameters:

1. Clarity of language of Screen reader software

2. Time taken by users to performed given task in both Screen

3. Reader software

4. Ease of use of screen reader software

5. Cost analysis of JAWS \& NVDA Screen Reader software

\section{Results of task 1:-}

Every group has been given 5 minutes to complete the task1. Graph 4 showed that elapsed time and three different standard's VIPs participated to perform the task1. The level of the screen of the JAWS Screen reader software take 2.2 for intermediate, 2.5 for high and 3 minutes for middle level.

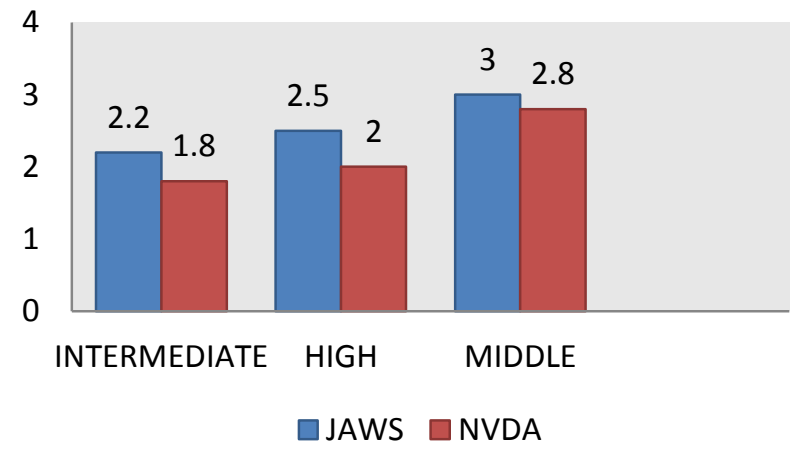

Graph 4:- Usability test results: Task 1 Results. 
NVDA screen reader take 1.8 for intermediate, 2 minutes for high and 2.8 for middle level. This time result shows that NVDA takes minimum time for all levels to complete their task.

\section{Results of task2:-}

However, the group two has been given to participate Graph 5 shows the time limit in minutes and three different standard's visual impaired persons (VIPs) participated to perform the task 2. JAWS Screen reader software take 2 minutes for intermediate, 2.8 minutes for high and 3.2 minutes middle level. NVDA screen reader take 1.6 for intermediate, 2 minutes for high and 2.8 for middle level. This time result shows that NVDA takes minimum time for all levels to complete their task. In this graph, primary level was not mentioned because the participant does not have an email account.

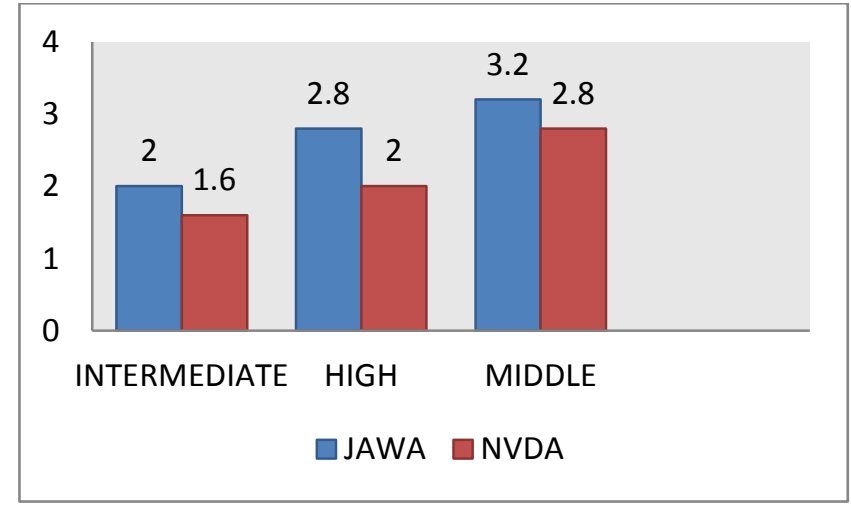

Graph 5:- Summary of task 2: Time taken by different age groups on two different software.

\section{Results of task 3:-}

The graph 6 shows the time limit 5 minutes and three different standard's VIPs participated to perform the task 3. The level of the JAWS Screen reader software for intermediate was 2.8 for high and 2.9 minutes for middle level. However, the 2.5 were middle level of JAWA software.

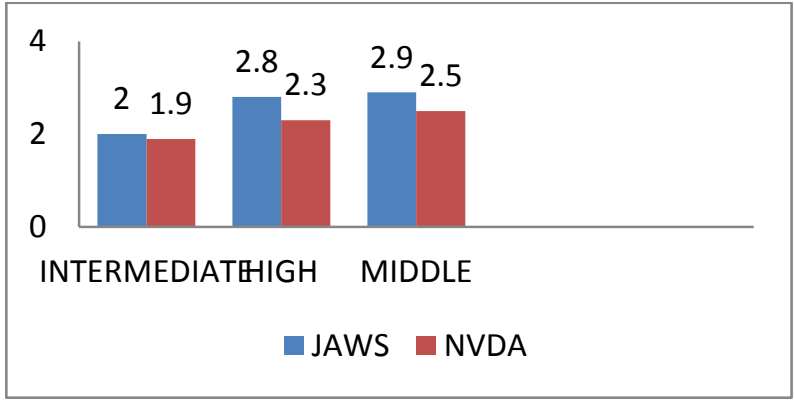

Graph 6:- Summary of task 3 performed by different age groups on two software for 5 minutes of time limit

NVDA screen reader take 1.9 for intermediate, 2.3 minutes for high and 2.5 for middle level. This time result showed that users on NVDA took minimum time for all levels to complete their task. In this graph, primary level is not mentioned because that participant did not have an email account.

\section{Average Perofrmance On All Three Tasks:-}

Pre test questionnaire with 3 tasks is summarized in graph 7. According to graph 7, the reading capabilities of all age groups found to be good on NVDA software comparing to the JAWS. It is clear that NVDA screen reader software takes 2.7 minutes in middle age group, 2.1 in high age group and 1.7 minute in intermediate age group. This is obvious that NVDA takes less time in comparison to JAWS screen reader in almost all age groups. 


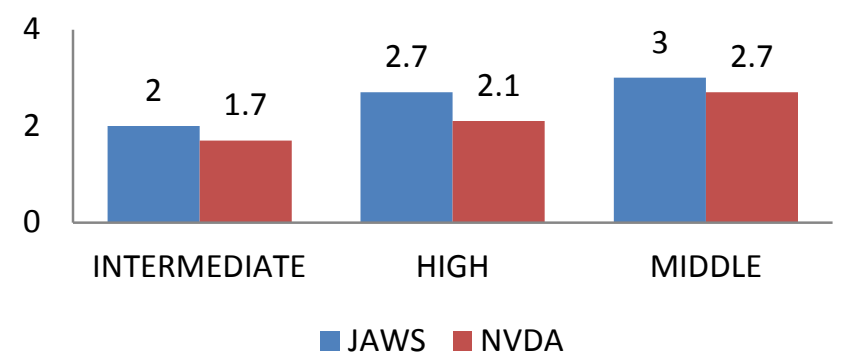

Graph 7:- The over all time consumption of participants on NVDA and JAWS software.

Table Utilization of screen reader software:-

Table utilization for both of the screen reader software is presented in graph 8. It is found that the both NVDA and JAWS screen reader software had employed the same table utilization.

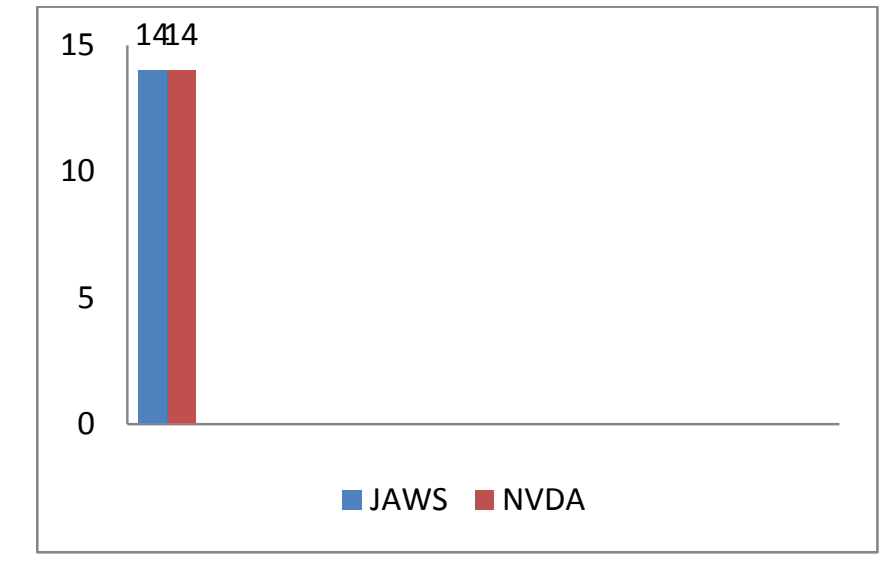

Graph 8:- Table utilization of NVDA and JAWS screen readers

\section{Easy Language by Screen Reader Software:-}

Graph 9 shows the language usage of JAWS and NVDA software. It was observed that students felt difficulty in understanding clearly the language used by JAWS screen reader software. Most of the participants find it an ambiguous language as compared to the NVDA screen reader.

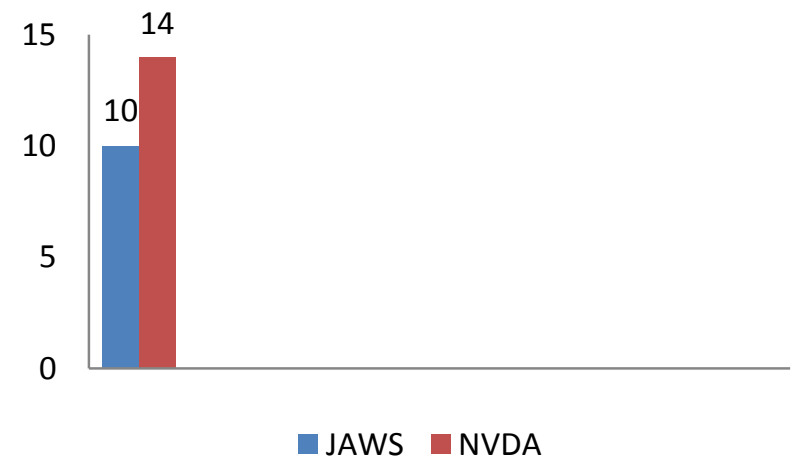

Graph 9:- Easy language usage of screen reader software.

It was observed that most of the participating students were satisfied with the language used by NVDA Screen reader software because of clearly pronounced and it is easy to understand. 


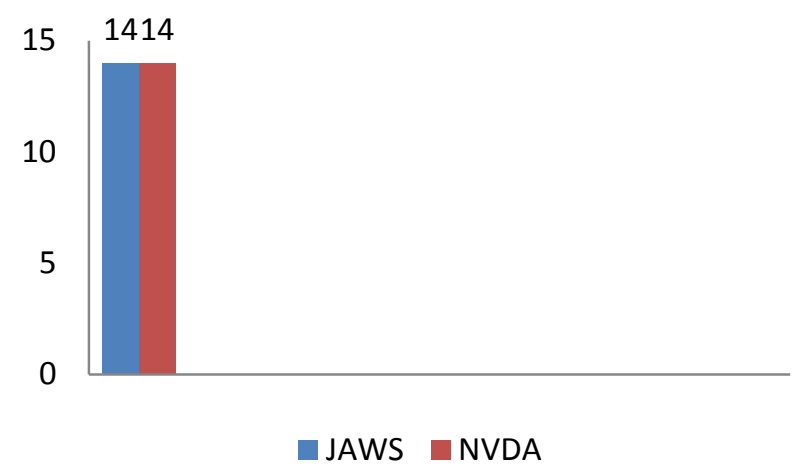

Graph 10:- Error detection and error recovery.

Graph 10 shows error detection and error recovery. Almost all participants find both software with good error detection, which is same in both JAWS \& NVDA screen reader software. All participants find Web browsing is easier in NVDA screen reader software than the JAWS. This concludes that NVDA screen reader has better browsing facility, which is showed in graph 11.

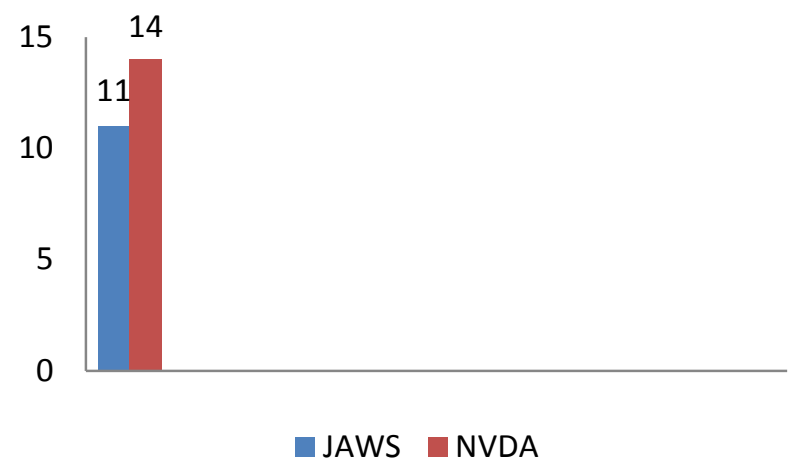

Graph 11:- Web browsing by screen reader software.

\section{Easy Installation and User Guide by Screen Reader Software:-}

It is clear that majority of participants were comfortable with easy installation of NVDA software comperatively to the JAWS as summarized in graph 12. NVDA is very easy to install in any individual desktop via a USB drive or it can be directly downloaded from internet, it is an open source software while JAWS can not be afforded by individuals.

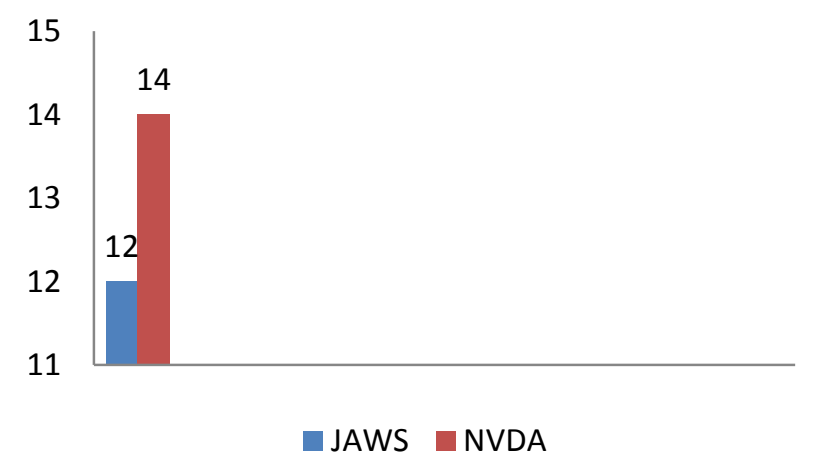

Graph 12:- Comparison of easy installation of software.

The user guide provided by screen reader software play a vital role for the users, if the user guide is easy in terms of language, installation, help, pronunciation and ascents, it would provide a better understanding to the VIPs/Blind users. NVDA proved as good screen reader software for this criterion. 


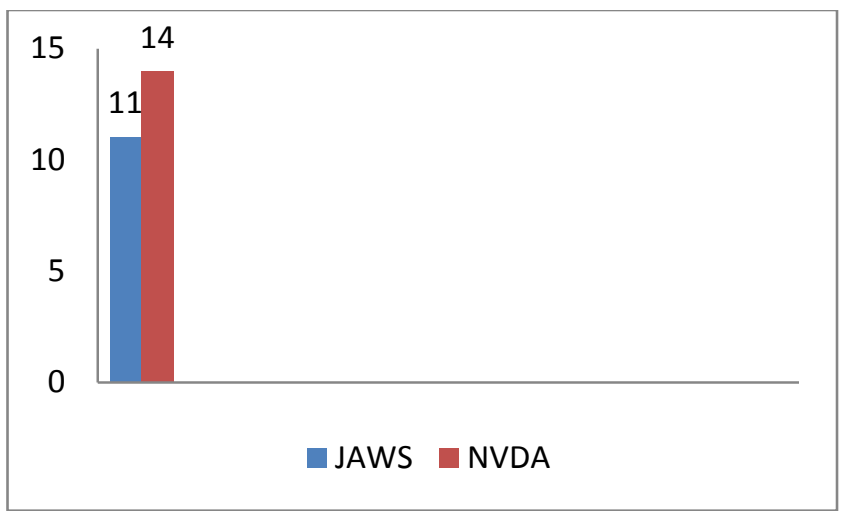

Graph 13:- Easy understanding of user guides provided in NVDA and JAWS screen readers software.

Short cut and access keys of screen reader software:-

Participants of all age groups find same shortcut keys in both JAWS and NVDA screen reader software, which is shown in following graphs 14-15. More access keys are available in JAWS screen reader software while NVDA has a few access keys.

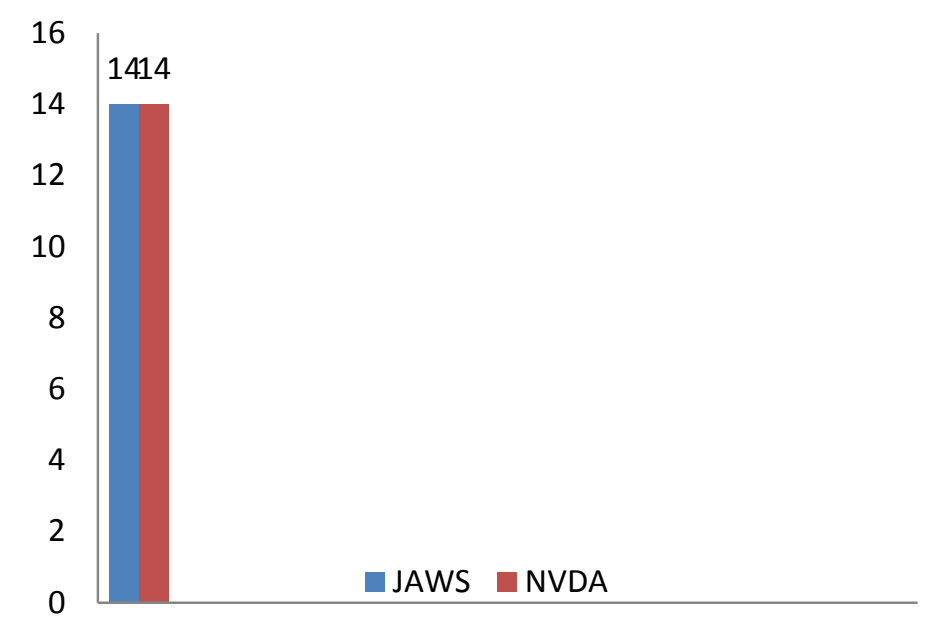

Graph 14:- Availability of short cut keys in screen reader software.

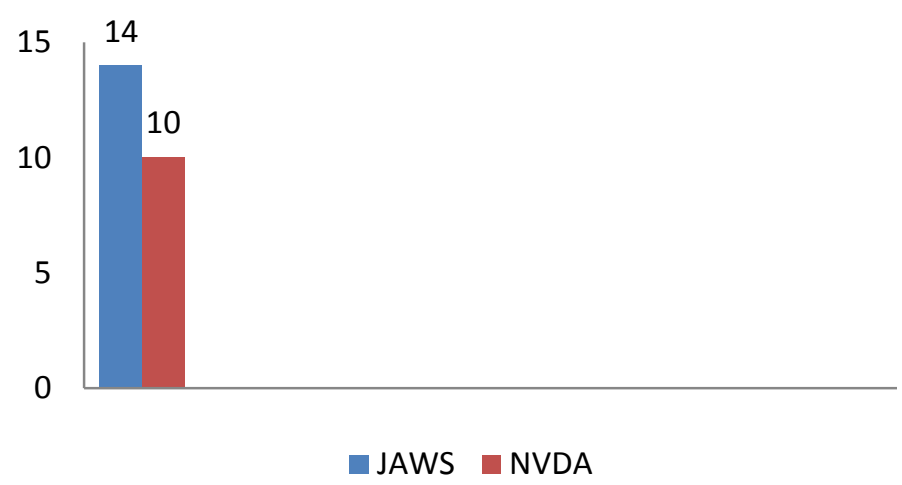

Graph 15:- Availability of Access keys in screen reader software.

Effective, Efficient \& ease of use Software:-

The participants of different age groups found NVDA screen reader software better and easy to understand than JAWS screen reader software. The overall performance of NVDA screen reader software was concluded as well as compared to the JAWS screen reader software in terms of efficiency, effectiveness and easy utilization. 


\section{Conclusion:-}

With the help of post questionnaire, it was revealed that that NVDA screen reader software shows good performance than JAWS. NVDA which is an open source screen reader, can read the percentage of installation, a dialogue box appear on the screen, which shows the status of installation while JAWS cannot read the percentage of installation. NVDA can recognize mouse tracking while the other cannot and it supports windows 7. NVDA supports Urdu language with easy and simple language utilization while offering few accessing keys. NVDA is more accessible with all computer applications than JAWS screen reader. The test participants are now using NVDA as their primary screen reader, which have introduced to them for the first time. The target of this research is to provide good screen reader software for these special persons so that they can utilize this software for carrying out their routine tasks in order to improve their life style.

\section{References:-}

1. Brian Kelly, Sarah Lewthwaite, and David Sloan; (2010) For Developing countries; developing experiences: approaches to accessibility for the real world", W4A '10 Proceedings of the 2010 International Cross Disciplinary Conference on Web Accessibility.

2. Woods, B., N. Watson. 2004. Wheelchairs as political machines. Paper presented at the Healthy Innovation Workshop, July 8-10, in Manchester.

3. Rosaria De Luca, Rocco Salvatore Calabrò, Giuseppe Gervasi, Simona De Salvo, Lilla Bonanno, Francesco Corallo, Maria Cristina De Cola, Placido Bramanti, (2014) Is computer assisted training effective in improving rehabilitative outcomes after brain injury? A case-control hospital-based study. Disability and Health Journal, Vol. 7, Issue 3, p356-360

4. Magdalena Wrzesińska, Klaudia Tabała, Patryk Stecz, (2016) The online behavior of pupils with visual impairment: A preliminary report. Disability and Health Journal, Vol. 9, Issue 4, p724-729.

5. Kent, B., and S. Smith. 2006. They only see it when the sun shines in my ears: Exploring perceptions of Adolescent hearing aid users. Journal of Deaf Studies and Deaf Education 11, no. 4: 461-76.

6. Ravneberg, B. (2009) Identity politics by design - users, markets and the public service provision for assistive technology in Norway. Scandinavian Journal of Disability Research 11, no. 2: 97 Ministry of Children and Equality 110

7. Söderström, S., Ytterhus, B. (2010). The use and non-use of assistive technologies from the world of information And communication technology by visually impaired young people: a walk on the tightrope of peer inclusion. Disability \& Society, 25(3), 303-315.

8. Vijaya Kancherla, Kim Van Naarden Braun, Marshalyn Yeargin-Allsopp (2013) Childhood vision impairment, hearing loss and co-occurring autism spectrum disorder. Disability and Health Journal, Vol. 6, Issue 4, p333342.

9. Chiang, M.F., R.G. Cole, S. Gupta, G.E. Kaiser, and J.B. Starren. 2005. Computer and world wide web accessibility by visually disabled patients: Problems and solutions. Survey of Ophthalmology 50, no. 4: 394-05.

10. Yod Samuel Martin Garcia, Beatriz San Miguel Gonzalez, and Juan Carlos Yelmo Garcia; (2009) for Prosumers and Accessibility: How to Ensure a Productive Interaction”, Eighteenth International World Wide Web Conference, 20-21st April 2009 Madrid, Spain

11. Sergio Sayago and Josep Blat; (2009) for About the Relevance of Accessibility Barriers in the Everyday Interactions of Older People with the Web", Eighteenth International World Wide Web Conference, 20-21st April 2009Madrid, Spain

12. Fänge A, Iwarsson S. (2005) Changes in accessibility and usability in housing: an exploration of the housing adaptationprocess, Occup Ther Int 12(1):44-59

13. Waldemar Karwowski, (2011) Human Factors and Ergonomics in Consumer Product Design: Methods and Techniques, Handbook of Human Factors in Consumer Product Design, June 22, 2011 by CRC Press, UK

14. Bevan, N., N. Claridge, M. Athousaki, M. Maguire, T. Catarci, G. Matarazzo, and G. Raiss; (2002) Guide to Specifying and evaluating usability as part of a contract", version1.0. PRUE project, Serco Usability Services: London. p.47.

15. Wickens, C.D et al. (2004). An Introduction to Human Factors Engineering (2nd Ed), Pearson Education, Inc., Upper Saddle River, NJ:, Prentice Hall

16. Gould, J.D., Lewis, C. (1985) Designing for Usability: Key Principles and What Designers Think", Communications Of the ACM, March 1985, Volume 28 Issue 3, March 1985 - 300 - 311 